\title{
Climate Considerations of the Electricity Supply Systems in Industries
}

\author{
Khabdullin Asset ${ }^{1}$, Khabdullina Zauresh ${ }^{2},{ }^{1-2}$ Rudny Industrial Institute
}

\begin{abstract}
The study is focused on analysis of climate considerations of electricity supply systems in a pellet industry. The developed analysis model consists of two modules: statistical data of active power losses evaluation module and climate aspects evaluation module.

The statistical data module is presented as a universal mathematical model of electrical systems and components of industrial load. It forms a basis for detailed accounting of power loss from the voltage levels. On the basis of the universal model, a set of programs is designed to perform the calculation and experimental research. It helps to obtain the statistical characteristics of the power losses and loads of the electricity supply systems and to define the nature of changes in these characteristics. Within the module, several methods and algorithms for calculating parameters of equivalent circuits of low- and high-voltage ADC and SD with a massive smooth rotor with laminated poles are developed.

The climate aspects module includes an analysis of the experimental data of power supply system in pellet production. It allows identification of GHG emission reduction parameters: operation hours, type of electrical motors, values of load factor and deviation of standard value of voltage.
\end{abstract}

Keywords - climate aspects, mathematical modeling, statistical data, power supply system, power loss, pellets production.

\section{INTRODUCTION}

The role of renewable energy resources is increasing due to climate considerations, energy independence and security reasons. Pellet production is considered a relatively high energy (electricity and heat) consumption industry [1-3]. However, methods for modeling and optimization of specific power systems, algorithms for calculating the characteristics of ADC and SD in the pellet industry are not well developed yet - mostly economic sustainability and total energy efficiency of the pellet production process and plant are examined [3-7] and rarely energy intensity [8]. Most existing algorithms for power systems analysis represent networks that are complex in structure and configuration, but normally are limited in voltage $-380 \mathrm{~V}$. In addition, the existing algorithms do not fully consider changes in parameters of the equivalent circuit diagram of ADC and SD [9-11].

Power units $P(U)$ and $Q(U)$ characterize the dependence of the active and reactive power load on the voltage at the node in the steady state. $P$ and $Q$ are widely used to solve a number of urgent problems of power supply (selecting and compensating devices and their management, voltage regulation at the nodes' load, etc.).Whereas, the selection of the statistical characteristic of active power losses $\Delta P_{\Sigma}(U)$ in the elements of electrical network and receivers (most of which- electric motors) powered by the node load has gained a significant interest [12-14, 16-17].
The ratio of the components (which ultimately determine the utilization rates of electric motors) depends strongly on the form of statistical characteristics of the power loss. Applied to guild system power supply (up to $1000 \mathrm{~V}$ ), they deserve special attention for the following reasons:

1. Conductor cross-section on a floor of sections or workshops of an industrial plant is not chosen by the economic current density, the permissible load current or the allowable voltage drop. Therefore, the maximum load creates higher values of the total power losses in the grid cell. Lengths of the craft networks are small, but sometimes the number of connections is large: for example, load of the transformer within a section of industrial plant is $S_{\text {nom }}=1000 \mathrm{kVA}$ on average and has more than 100 connected power users by collectors.

2. A greater share of load in the electricity supply system (SES) is generated from asynchronous motors (AM) with squirrel cage capacity of $1 \mathrm{~kW}-4 \mathrm{~kW}$ and synchronous motors (SM) with a massive rotor, the efficiency of which is in the range $0.75-0.90$. It means that the losses of power in the fractions of the power consumption are commensurate with the total power losses in all previous stages of transformation.

3. The average load factor of AM and SM of electricity supply systems' sections (active power) is in the range of $\mathrm{K} 3=0.5-0.7$.

Analysis of statistical data of power consumption at the pellet production industry was investigated by H.Vigants et.al. [18]. The study focuses on use of correlation analysis to define a mathematical model for the energy consumption analysis at the plant aimed to introduce cleaner production at the industry. The authors concluded that the amount of electricity produced at the pellet production-related cogeneration plant depends on the cogeneration plant power consumption and the power consumption of the pellet production facility.

Determination of the statistical characteristics of the power losses by physical experiments is feasible in practise. Some issues are connected with branching of the workshop's electrical network, others - with the differences in number of lengths. However there is a great variety of types of power end user technologies: for example from several tens to several hundreds of different types of electric motors with a wide range of output $(0.3 \mathrm{~kW}$ to $400 \mathrm{~kW})$.

\section{METHODS}

Analysis of climate considerations of electricity supply systems in a pellet industry is divided in two parts: (1) technical analysis of statistical data of electrical systems for 
$2014 / 13$

definition of power losses and (2) relocation of the technical electrical systems data to climate parameter.

Analysis of the statistical characteristics of the power losses is based on the following measures:

- normalisation process: determination of the parameters of equivalent circuits of electric motors from the list of industrial equipment and technical document data;

- assessment of assumptions: calculation of the steady regime of electricity supply system with arbitrary values of configuration and structure of system;

- creation of data base: the particular package of mapping of equipment placement area and service programs on the PC.

A detailed algorithm for calculating the parameters of the equivalent circuit is described in $[9,11]$.

Analysis of climate considerations, expressed in the paper through greenhouse gas (GHG) emissions, observed in the paper through unwelcomed power losses. Calculation of the GHG is based on equation (1).

$$
\mathrm{CO}_{2}=R \Delta P t, t_{\mathrm{CO} 2} / \text { year }
$$

where

$\mathrm{CO}_{2}$ - annual increase of GHG emissions created by power losses, $t_{\mathrm{CO} 2} /$ year;

$R-\mathrm{GHG}$ emission factor, for coal $R=0.342 \mathrm{tCO}_{2} / \mathrm{MWh}$;

$\Delta P$ - power losses, MW,

$t$ - operation hours per year, h/year.

Since the heat and electricity supplied to the pellet production plant is generated from coal, the GHG emission factor of coal is used in the calculations.

\section{EXPERIMENTAL MODEL}

The power supply system of the pellets production workshop (PPW) substations TP-26 JSC "SSGPO" (Figure 1) is selected for studies of statistical characteristics of power loss.

Power supply of PPW is provided from the substations - SS № 34 (SS 110/6 and 35/6). Power supply of the mechanical plot is provided by a double transformer substation № 26 6/0, $4 \mathrm{kV}$ transformers through 1,000 kVA each. In turn, substation № 26 is powered by a mutual reserve current distributor, laid on the ground, from double transformer substation № 34. The substation № 34 set 2x(40 MVA) transformer $110 / 6$ and $35 / 6 \mathrm{kV}$, power supply of substation № 34 is provided from OL SarbaiAgglomerat № 1 with voltage $110 \mathrm{kV}$ from substation "Sarbai" JSC «KEGOC» and by OL voltage $35 \mathrm{kV}$ from the heat power station. [15]

The total number of electricity supply system elements is 352, including cables (117 connections with total length of about $9000 \mathrm{~m}$, range of lengths of connections - from $10 \mathrm{~m}$ to $180 \mathrm{~m}$, range cable cross sections are from $2 \times(3 \times 240)$ to $3 \times 4 \mathrm{~mm}^{2}$ ) and also $91 \mathrm{AM}$ and $12 \mathrm{SM}$ with a total installed capacity of $18 \mathrm{~kW}$; and the average engine power $174 \mathrm{~kW}$ (twenty have a capacity of over $100 \mathrm{~kW}: 2$ of 2000, 10 of 800 , 4 of 500 and 4 of $400 \mathrm{~kW}$ minimum power $-0.5 \mathrm{~kW}$ ). Other (non-motor) load, equal to $0.38 \mathrm{kV}$, consists of the lighting, alarms and thyristor stimulating devices (TSD) of the SD.

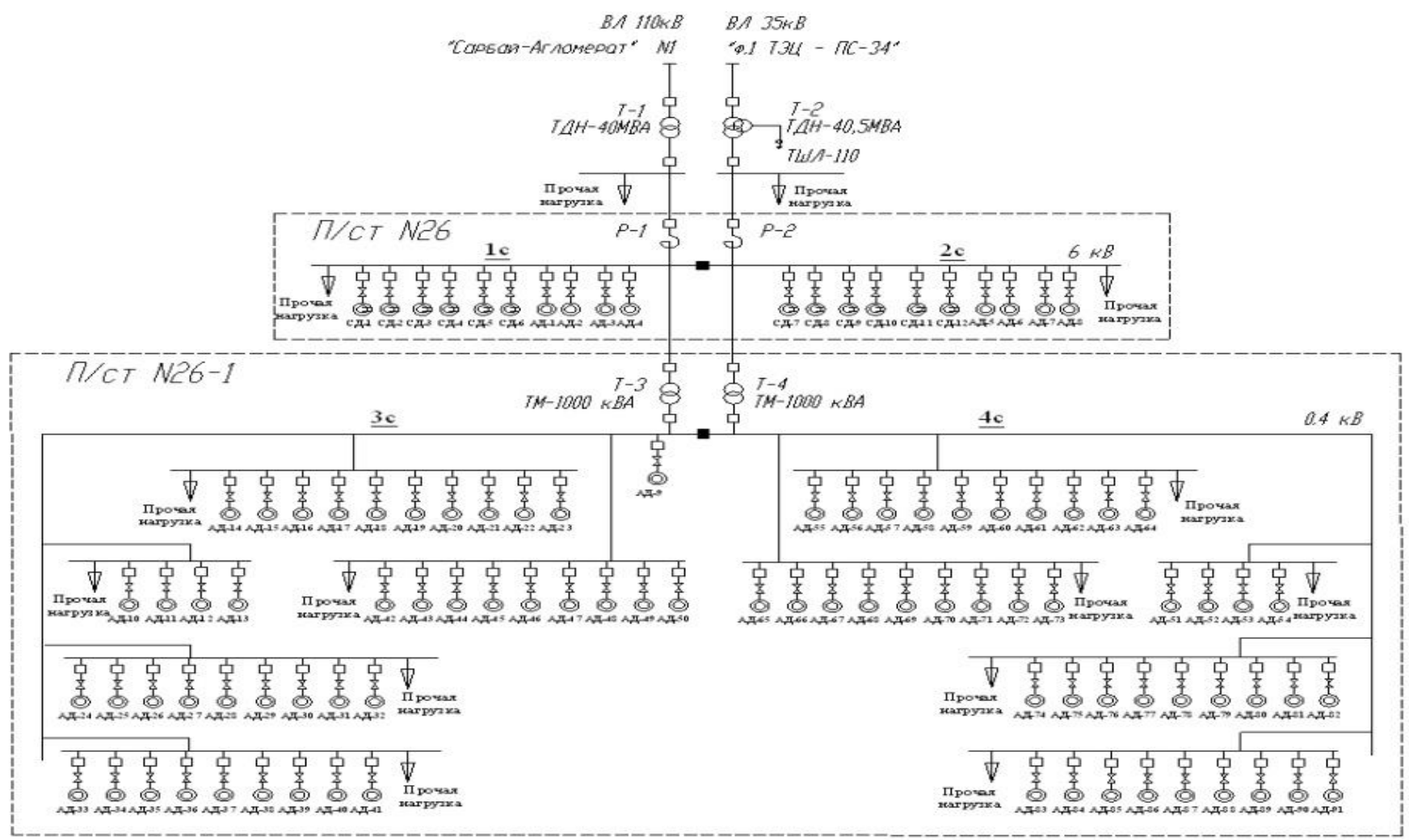

Fig. 1. Design diagram TP-26 JSC «SSGPO». 


\section{RESUlTS}

Figure 2 shows the statistical characteristics of the total active power losses versus deviation of voltage standard value for the load factor $\left(\mathrm{K}_{3}\right)-0.9$ and $0.8 \mathrm{AM}$ and SM. The notation: $\Delta P_{\Sigma \mathrm{SM}}$ - total active power losses in the $\mathrm{SD}$ (including losses in the motor circuit connection); $\Delta P_{\Sigma \mathrm{AM}}-$ the total loss of active power in in the fractions of the power consumption (including losses in the chain connecting engines); $\Delta P_{\text {network }}$ - active power losses in the networks; $\Delta P_{\Sigma \text { transformer }}$ - total active losses in transformers; $\Delta P_{\Sigma}$ - the total

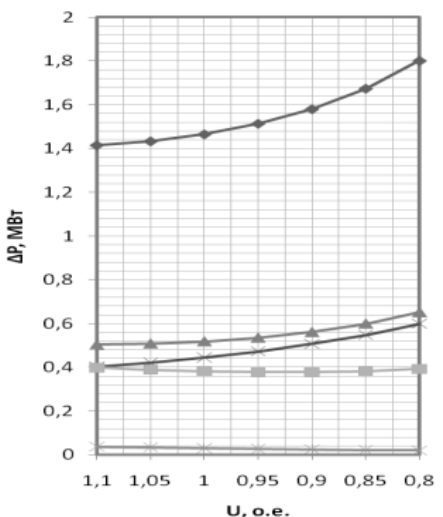

a) active power loss in the SES, including active power losses in the network, AM and SM.

Figure 3 shows the statistical characteristics of the total active power losses in this scheme versus deviation of voltage standard value for the load factor $\mathrm{K}_{3}=0.9$ and 0.8 . The notation: $\Delta P_{\Sigma \mathrm{AM}}$ - the total active power losses in AM (which includes losses in the motor circuit connection); $\Delta P_{12 \mathrm{AM}}$ - total active power losses in the steel magnet systems of AM; $\Delta P_{1 \mathrm{AM}}$ - total active power losses in the stator windings of AM; $\Delta P_{2 \mathrm{AM}}$ - total active power losses in the rotor windings of $\mathrm{AD}$; $\Delta P_{\Sigma \text { AMcab }}$ - total active power losses in joining AM.

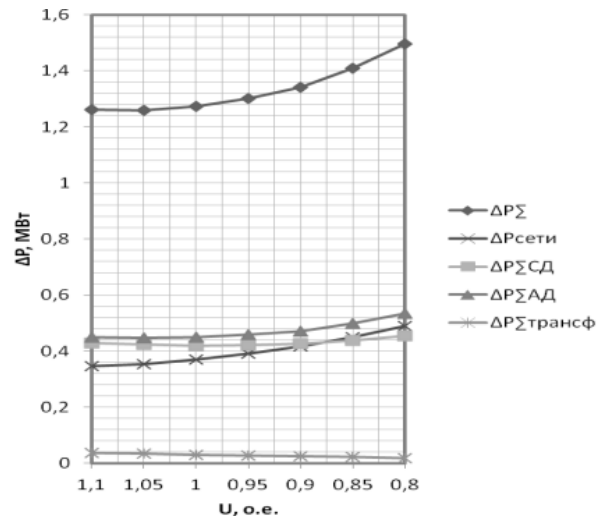

b)

Fig. 2. Statistical characteristics of the active power losses for TP-26: a) when $K_{3}=0.9$, b) when $K_{3}=0.8$.

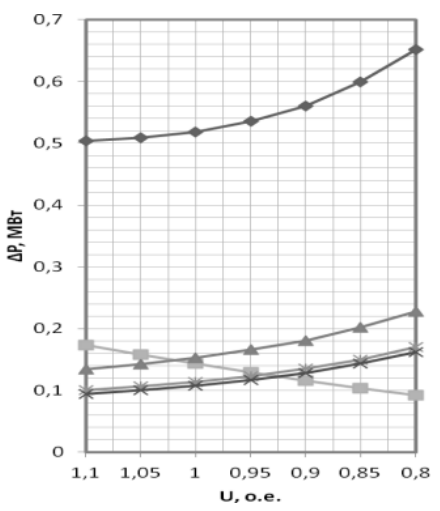

a)

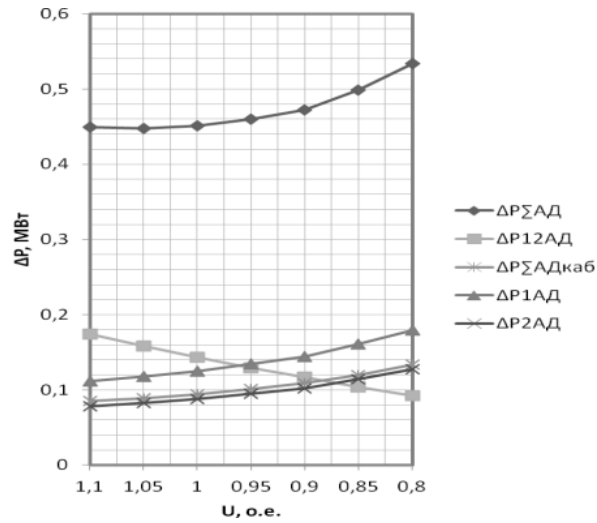

b)

Fig. 3. Statistical characteristics of losses active power in AM: a) when $\mathrm{K}_{3}=0.9$ b) when $\mathrm{K}_{3}=0.8$

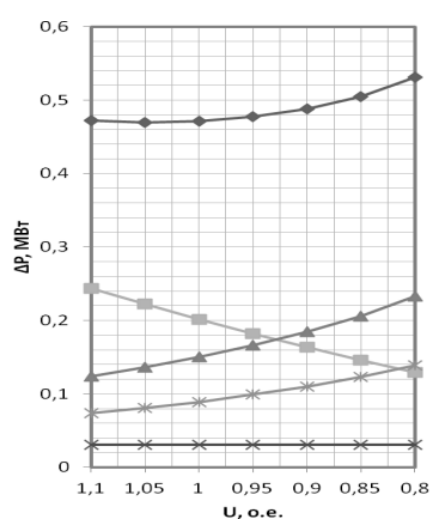

a)

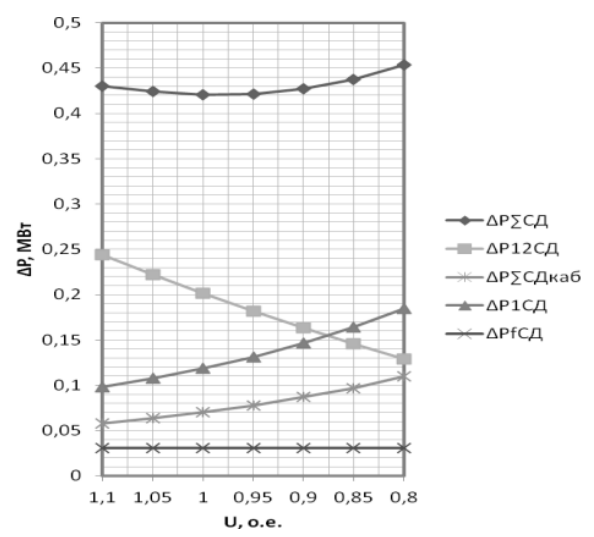

b)

Fig. 4.Statistical characteristics of losses active power in SM: a) when $\mathrm{K}_{3}=0.9$; $\mathrm{b}$ ) when $\mathrm{K}_{3}=0.8$ Similar structural properties were built for the TP-26 JSC "SSGPO" at K3 $=0.7,0.6,0.5$, AM and SM 
$2014 / 13$

Figure 4 shows the statistical characteristics of the total active power losses SM in this scheme versus deviation of voltage standard value for the load factor $K_{3}=0.9$ and 0.8 . The notation: $\Delta P_{\Sigma \mathrm{SM}}$ - total losses of active power SM (including losses in the motor circuit connection); $\Delta P_{12 \mathrm{SM}}$ - total active power losses in magnetic systems of SM; $\Delta P_{1 \mathrm{SM}}$ - total active power losses in the stator windings of SM; $\Delta P_{\mathrm{fAM}}$ - total active power losses in the windings of the excitation SM; $\Delta P_{\Sigma \text { SMcab }}-$ total active power losses in joining to SM.

\section{DISCUSSION}

The completed numerical and experimental investigation of the statistical characteristics of power capacity and power losses in the power supply system showed that the total active power losses in the workshop SES are from $6.5 \%$ to $9.1 \%$ of the total power consumption, however the proportion of active power losses in AM are in the range from $70 \%$ to $85 \%$ of the losses in the SES.

The overall efficiency of the electric motor load reaches $89.8 \%-95.6 \%$ and most of the active power consumption of $\mathrm{AM}$ and SM relates to a high efficiency process $\left(P_{\text {nom }}>100 \mathrm{~kW}\right)$.

1. Terminal voltage transformers T1, T2 TP-26 (JSC "SSGPO"), at which the minimum of the total active power losses occurs, depends essentially on the load factor and varies with the load factor of 1 to 0.5 in the range of 1.1 to 0.85 of nominal.

2. In the active load TP-26, the overwhelming share $(\approx 80 \%)$ of power consumed by AM and SM, so the consumption of active power, depends strongly on the voltage at the transformer station TP. When the voltage is $10 \%$ of active power, consumption at $\mathrm{AM}$ is reduced by $3 \%-5 \%$.

Power losses in the electricity network system create an increase in greenhouse gas (GHG) emissions in power production in condensing power plants fueled by coal.

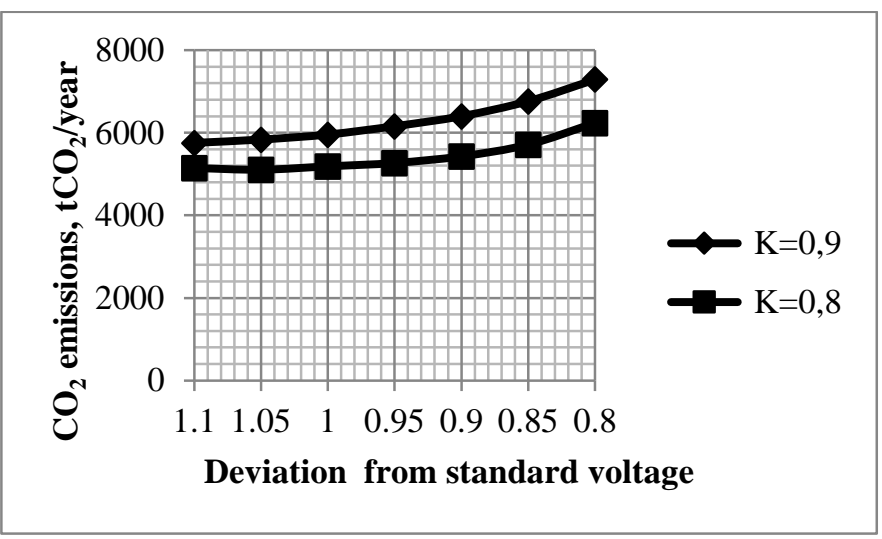

Fig. 4. Reduction of GHG emissions in Substation TP-26.

As shown in Fig. 4, deviation from the standard voltage creates not only energy losses in the electricity supply system, but also creates an effect whereby GHG emissions increase. It is significant to note, that increase of load factor $\mathrm{K}$ causes an increase of unjustified GHG emissions to the environment.

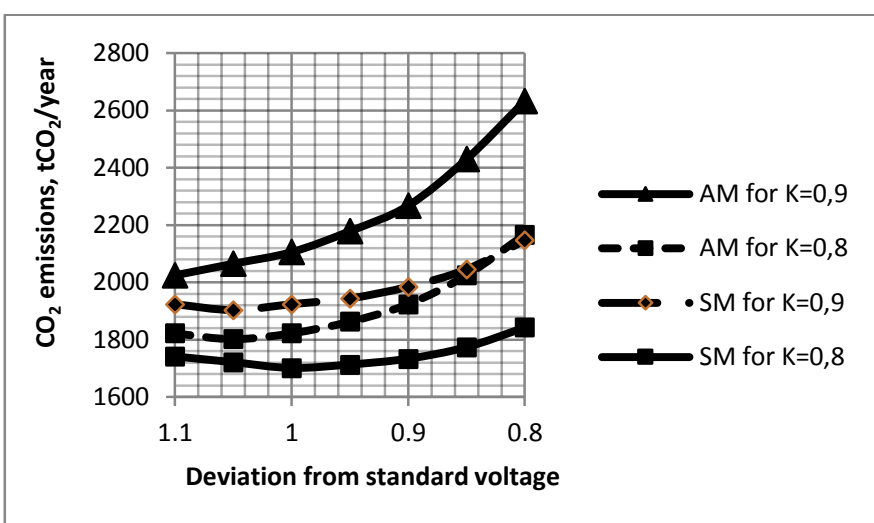

Fig. 5. Reduction of GHG emissions form asynchronous (AM) and synchronous (SM) motors.

Similar impact on climate change results from the use of asynchronous and synchronous motors where the reduction of GHG emissions is larger in cases when an asynchronous motor is used.

The modeling of reductions in climate change impact is associated with the management and optimization tasks of the operations of the electricity supply system. The analysis of experimental data of the power supply system in pellet production allowed to identify GHG emission reduction parameters: operation hours, type of electrical motors, values of load factor and deviation of standard value of voltage.

\section{REFERENCES}

1. Thek, G., Obernberger, I. Wood pellet production costs under Austrian and in comparison to Swedish framework conditions. Biomass and Bioenergy, 2004, No. 27, pp. 671-693. http://dx.doi.org/10.1016/j.biombioe.2003.07.007

2. Uasuf, A., Becker, G.. Wood pellets production costs and energy consumption under different framework conditions in Northeast Argentina. Biomass and Bioenergy, 2011, No. 35, pp. 1357-1366. http://dx.doi.org/10.1016/j.biombioe.2010.12.029

3. Agar, D., Gil, J., Sanchez, D., Echeverria, I., Wihersaari, M. Torrefied versus conventional pellet production - A comparative study on energy and emission balance based on pilot-plant data and EU sustainability criteria. In press, Applied Energy, 2014. Available online on 4 September 2014.

4. Trømborg, E., Ranta, T., Schweinle, J., Solberg, B., Skjevrak, G., Tiffany, D. G. Economic sustainability for wood pellets production - A comparative study between Finland, Germany, Norway, Sweden and the US. Biomass and Bioenegy, 2013, No. 57, pp. 68-77. http://dx.doi.org/10.1016/j.biombioe.2013.01.030

5. Uasuf, A., Becker, G. Wood pellets production costs and energy consumption under different framework conditions in Northeast Argentina. Biomass and Bioenegy, 2011, No. 35, pp. 1357-1366. http://dx.doi.org/10.1016/j.biombioe.2010.12.029

6. Stahl, M., Berghel, J. Energy efficient pilot-scale production of wood fuel pellets made from a raw material mix including sawdust and rapeseed cake. Biomass and Bioenegy, 2011, No. 35, pp. 4849-4854. http://dx.doi.org/10.1016/j.biombioe.2011.10.003

7. Song, H., Dotzauer, E., Thorin, E., Yan, J. Annual performance analysis and comparison of pellet production integrated with an existing combined heat and power plant. Bioresource Technology, 2011, No. 102, pp. 6317-6325. http://dx.doi.org/10.1016/j.biortech.2011.02.042

8. Wolf, A., Vidlund, A., Andersson, E. Energy-efficient pellet production in the forest industry-a study of obstacles and success factors. Biomass and Bioenegy, 2006, No. 30, pp. 38-45. http://dx.doi.org/10.1016/j.biombioe.2005.09.003

9. Boglietti, A., Cavagnino, A., Lazzari, M. Induction motor model for taking into account additional losses", International Conference "ICEM 2006”, Crete Island, Greece, 02-05 September 2006. 
10. Boglietti, A., Cavagnino, A., Ferraris, L., Lazzari, M. Induction Motor Equivalent Circuit Including the Stray Load Losses in the Machine Power Balance. Energy Conversion, IEEE Transactions on Energy Conversion, 2008, Vol. 23, No. 3, pp. 796-803.

http://dx.doi.org/10.1109/TEC.2008.921467

11. Gamazin, S. I., Stavtsev, V. A., Tsyruk, S. A. Transients in industrial power supply, resulting electric motor load. - M.: PublishingMEI, 1997. 424 p.: Ill.

12. Gmyrek, Z., Boglietti, A., Cavagnino, A. Estimation of Iron Losses in Induction Motors: Calculation Method, Results, and Analysis. Industrial Electronics, IEEE Transactions on Energy Conversion, 2010, Vol. 57, No. 1, pp. 161-171.

13. Auinger, H. Energy efficiency Improvements in Electric Motors and Drives. Springer-Verlag, 1997. $511 \mathrm{p}$. http://dx.doi.org/10.1007/978-3-642-60832-2_22

14. Zhang, H., Zanchetta, P., Gerada, C., Bradley, K., Junyi, L. Performance evaluation of induction motor efficiency and in-service losses measurement using standard test methods. Electric Machines \& Drives Conference (IEMDC), 2011 IEEE International, pp. 913-917.

15. Khabdullin, A. B. Optimization of power losses in electric networks. Problems of Electrical Engineering, Electricity and Electrical Technologies. Proceedings of the International Scientific and Technical Conference. Part 2. Togliatti: Togliatti State University Press, 2009. pp. 69-72.

16. Pitis, C. D., Zeller, M. W. Power savings obtained from supply voltage variation on squirrel cage induction motors. Electric Power Conference, 2008. EPEC 2008. IEEE Canada, pp. 1-3.

17. Kellogg, S. D., Grady, W. M. A Linearized Procedure for Voltage Control. Electric Power Systems Research, 1990, No.18, pp. 23-26.

18. Syromyatnikov, I. A. Modes of operation of synchronous and asynchronous motors. - M. Energoatomizdat.

19. Vigants, H., Uuemaa, P., Veidenbergs, I., Blumberga, D. Cleaner pellet production - an energy consumption study using statistical analysis. Agronomy Research, 2014, No. 12 (2), pp. 633-644.

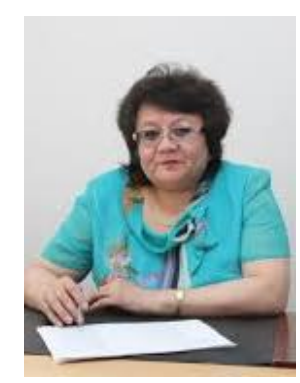

Khabdullina Zauresh graduated Pavlodar Industrial Institute "Power" in 1983. In 1993 she defended her thesis at the Moscow Power Engineering Institute and received the title of Candidate of technical sciences. In 2013, successfully defended her doctoral dissertation and received the title of Doctor of Technical Sciences. Khabdullina Zauresh works as the head of the department on "The electric power industry and power engineering" of the Rudny Industrial Institute. Zauresh has published her scientific results in leading academic and technical journals of the CIS countries, Bulgaria, Poland and presented at numerous international and Internet conferences. Khabdullina Zauresh is awarded with several diplomas and letters of honours for her professional activities. Zauresh twice won the grant of Ministry of Science of the Republic of Kazakhstan and was awarded "Best teacher of high school of the Republic of Kazakhstan" in 2006 and 2012

Address: 50 Let Oktobra Street 38, 111500, Rudny, Kazakhstan.

E-mail: habdullina@rii.kz

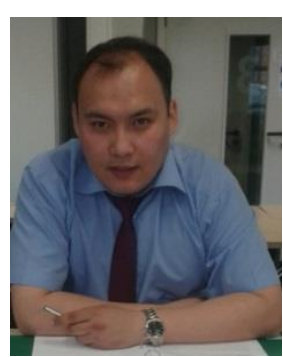

Khabdullin Asset graduated master programme on Industrial electricity in 2007 and enrolled in full-time training at the Moscow Power Engineering Institute (Technical University). In 2012 he defended his thesis for the degree of Candidate of technical sciences in "Electrical equipment and systems". Khabdullin is the dean of the faculty "Energy and Information Systems" in Rudny Industrial Institute and works there also as a senior lecturer on "Power and Electrification". Khabdullin Asset has published his scientific results in leading academic and technical journals

of the Czech Republic, Bulgaria, Turkey and presented those at international conferences, meetings, online conferences, and published more than 40 scientific publications and teaching materials. Khabdullin Asset develops and implements projects in the energy field for enterprises of the Northern region of Kazakhstan, examines scientific competitive projects of the Ministry of Science of the Republic of Kazakhstan and enterprises, conducts training for employees of enterprises.

E-mail: aset85@mail.ru 